\title{
Nearshore Sand Bars
}

\author{
Francesca Ribas, Albert Falqués, and Roland Garnier
}

\begin{abstract}
This review summarizes the morphological characteristics and dynamics of nearshore sand bars observed in the surf zone of sandy beaches worldwide, with length scales ranging from tens to hundreds of meters and time scales ranging from hours to weeks. They include shore-parallel bars (straight and crescentic) and transverse bars of different types. Furthermore, the present knowledge on the physical processes behind their formation and development is discussed.
\end{abstract}

\section{Keywords}

Shore-parallel bars - Crescentic bars - Transverse bars - Physical processes Self-organization - Sediment transport $\bullet$ Coastal morphodynamics

\subsection{Motivation}

Subtidal nearshore bars are sand deposits (i.e. shallow areas) occurring in the surf zone of sandy beaches. They have been observed on both open and protected coasts, with fine to medium sand and surf-zone slopes smaller than 0.05, in predominantly nontidal to microtidal settings (they have been occasionally reported on beaches with a significant tidal range) (Wijnberg and Kroon 2002; Van Enckevort and Ruessink 2003). They are important because waves dissipate part of their energy on the bars and the bars can also provide sand to the beach if they migrate onshore (Ribas et al. 2015). Furthermore, alongshore rhythmic bars (Fig. 13.1b) can have a direct impact on the shoreline by creating areas of erosion and deposition, and they are coupled to spatial patterns in surf zone currents (e.g. rip currents) that affect transport and exchange of pollutants, plankton, nutrients or other floating matter. Rip currents are also dangerous for

F. Ribas $(\varangle) \cdot$ A. Falqués

Department of Physics, Universitat Politècnica de Catalunya,

Barcelona, Spain

e-mail: francesca.ribas@upc.edu

R. Garnier

Environmental Hydraulics Institute (IH Cantabria),

Universidad de Cantabria, Santander, Spain swimmers, being one of the most lethal natural hazards worldwide. Moreover, studying the sand bar dynamics allows us to identify important physical mechanisms that control coastal evolution. In particular, it increases our understanding of the effective sediment transport in areas of the coastal zone (e.g. the swash zone and the inner surf zone) where there is still a significant lack of knowledge on this important process.

This article is a short review of the morphological characteristics and dynamics of the different types of nearshore bars (Sect. 13.2) and the physical processes behind their evolution (Sect. 13.3). Furthermore, Ribas et al. (2016) describes observations of nearshore sand bars on beaches of the western Mediterranean Sea.

\subsection{Classification and Morphological Characteristics and Dynamics}

\subsubsection{Shore-Parallel Bars (Straight or Crescentic)}

One to three shore-parallel bars are frequently observed on micro- to mesotidal beaches worldwide (van Enckevort et al. 2003). They are elongated, narrow, shore-parallel ridges that 


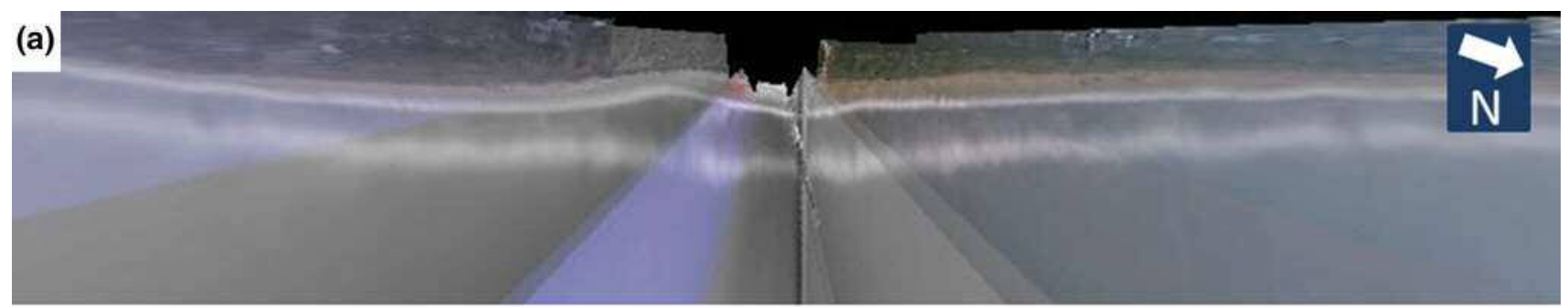

(b)

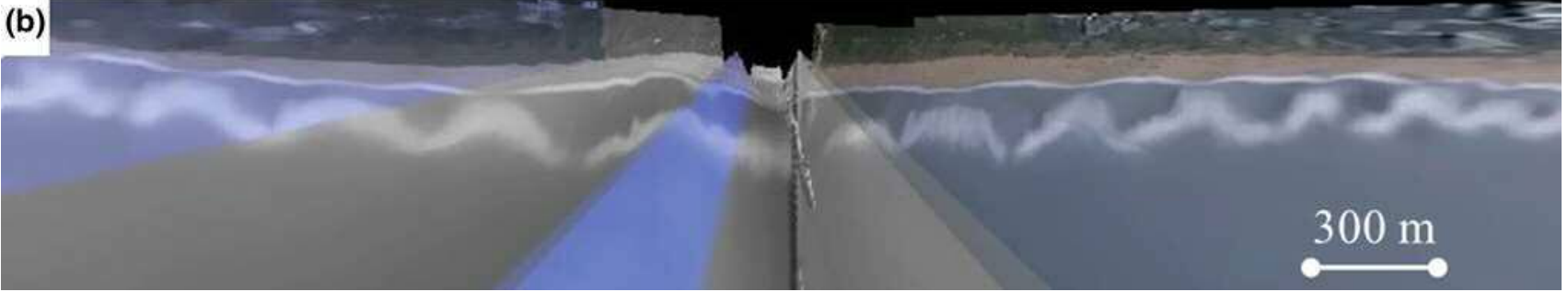

Fig. 13.1 Transition between a straight bar (a) and a crescentic bar (b), (mean wavelength of about $300 \mathrm{~m}$ ) at Duck beach, USA, in August-September 1998. The plan views of the beach are created from time-averaged video-images, where the white zones indicate bar presence due to preferable wave breaking on the shallows. The coastline is at the top. Images courtesy of Dr Nathaniel Plant, USGS, USA are separated from the shoreline by a deeper area or trough. Gentler nearshore slopes seem to favour a larger number of bars (Wijnberg and Kroon, 2002). They can vary in configuration from alongshore-uniform or straight bars (Fig. 13.1 a) to crescentic bars that undulate in plan view (Fig. 13.1b) (Wright and Short 1984). Sometimes the undulation is quite subtle, the bar being almost straight, but sometimes it is very pronounced, featuring crescent moons with the horns (shoals) pointing shoreward and the bays (deeps) located seaward (van Enckevort et al. 2004). Crescentic bars are sometimes called rip channel systems because strong rip currents always flow offshore in the deep areas, which are called rip channels. On the other hand, straight bars are sometimes slightly oblique instead of being alongshore-parallel (Guillén and Palanques 1993).

The wavelength or alongshore spacing between rip channels (i.e. between crescentic bar horns) tends to be relatively constant alongshore and ranges from tens of metres up to 2-3 km (van Enckevort et al. 2004). Very often, along beaches with crescentic bars the shoreline features undulations with a similar wavelength. Since this wavelength is typically larger than the spacing between ordinary beach cusps, they are called megacusps (Wright and Short 1984). The horns of the crescentic bars can connect to the shoreline and to the megacusp system during long-lasting conditions of low wave energy (down-state transition, see Wright and Short (1984) and Ranasinghe et al. (2004)). The resulting transverse bar system (Fig. 13.2 and $13.3 \mathrm{~b}$ ) is one of the four different types of transverse bar systems that will be discussed in Sect. 13.2.2.
Apart from the slow onshore migration that crescentic bars experience during the down-state transition, at rates of $\mathrm{O}(1 \mathrm{~m} / \mathrm{d})$, crescentic bars can also migrate alongshore in the downdrift direction in the case of oblique wave incidence at rates of up to $\mathrm{O}(100 \mathrm{~m} / \mathrm{d}$ ) (van Enckevort et al. 2004). During storms of certain characteristics (see Sect. 13.2.2), crescentic bars become straight and migrate offshore at rates of $\mathrm{O}(10 \mathrm{~m} / \mathrm{d})$ (Ruessink et al. 2009). Finally, at longer inter-annual time scales, the shore-parallel bars on open multi-barred beaches experience the following cycle: bar formation near the shoreline, net offshore migration for one or more years, and decay in deep water (van Enckevort and Ruessink 2003, among others). The duration of the cycle varies from about a year (observed at a Japanese site) to more than a decade (observed at several Dutch sites) (Ruessink et al. 2009). On embayed single-barred beaches, the net offshore migration trend is not observed (Ranasinghe et al. 2004; Ojeda et al. 2011).

\subsubsection{Transverse Bars}

The second kind of nearshore sand bars are generally called transverse bars because they are typically attached to the shoreline and extend offshore either in the shore-normal direction or with an oblique orientation in case of oblique wave incidence. If the crests are shifted in (against) the direction of the alongshore current, we use the term down-current (up-current) oriented bars. Several transverse bars separated by an approximately constant alongshore 
Fig. 13.2 Transverse bars at Palm beach, Australia, corresponding to type 1 (TBR bars), with spacing between bars of a few hundred metres. Photograph taken by the authors

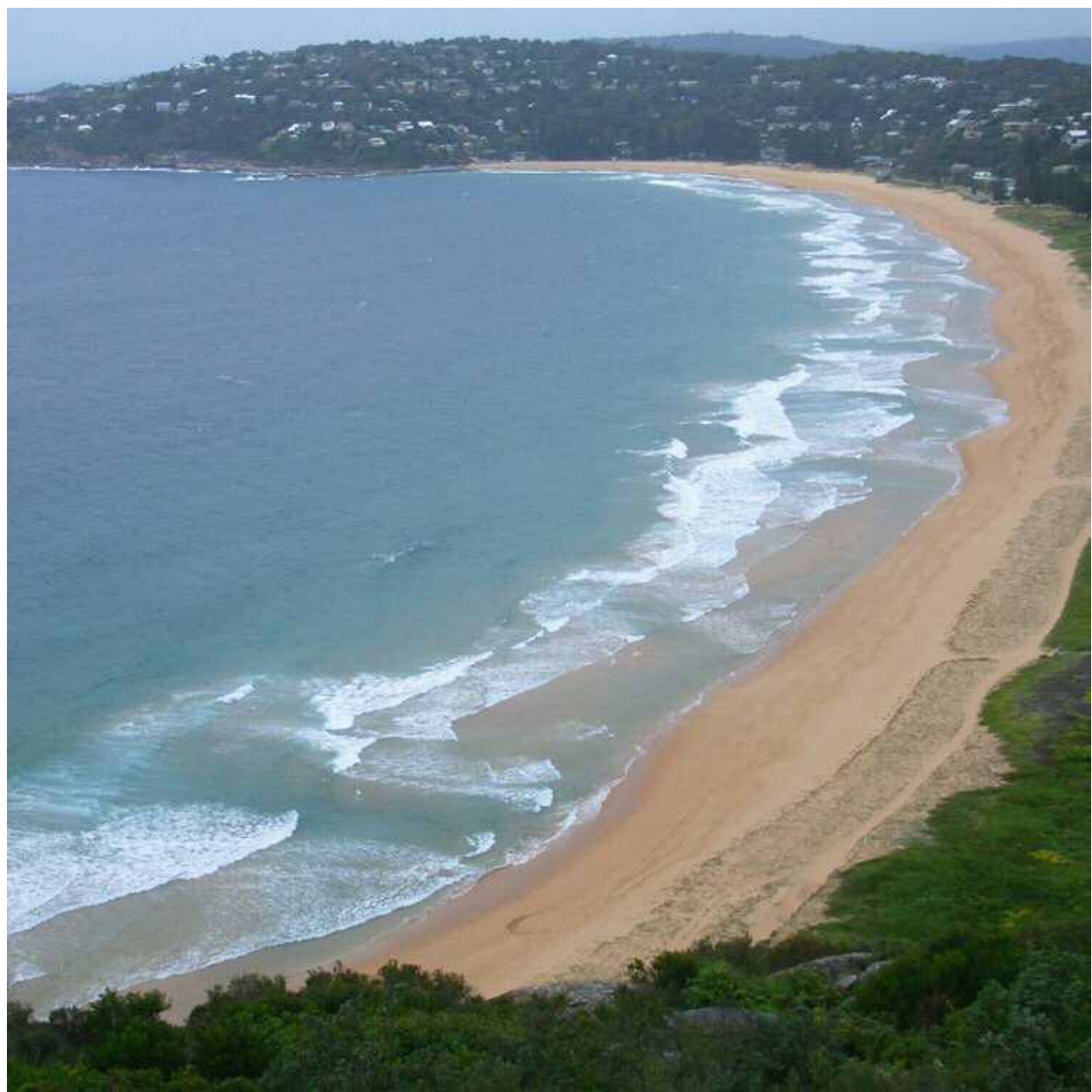

distance are often observed (Fig. 13.2). In the presence of an alongshore current, they migrate downdrift with migration rates of up to $40 \mathrm{~m} / \mathrm{d}$ (Hunter et al. 1979; Konicki and Holman 2000; Ribas and Kroon 2007; Pellón et al. 2014). Four different types of transverse bars have recently been characterized (Pellón et al. 2014; Ribas et al. 2015).

Type 1: TBR bars (Figs. 13.2 and 13.3b). The most common type is that corresponding to the transverse bar and rip (TBR) state in the standard beach state classifications (Wright and Short 1984). The TBR bars are commonly observed on open microtidal beaches under medium-energy conditions. They are typically wide and short-crested and their origin is the merging of a crescentic bar into the beach (see Sect. 13.2.1), so their spacing is strongly related to that of the pre-existing crescentic bar. They can be approximately perpendicular to the shore when shore-normal waves dominate, or down-current oriented (Fig. 13.3b) when incoming waves arrive with a predominant obliquity (Holman et al. 2006; Castelle et al. 2006). As in the case of crescentic bars, TBR bars also show strong and narrow rip currents flowing seaward in the troughs and wider and weaker onshore flows over the crests.
Type 2: Medium-energy finger bars (Fig. 13.3d). These transverse bars have been observed on open microtidal beaches under medium-energy conditions (Konicki and Holman 2000; Ribas and Kroon 2007) and they always coexist with shore-parallel (or crescentic) bars. The term finger bars refers to their thin and elongated nature, and distinguishes them from the wider and shorter TBR bars. These bars are ephemeral, having a residence time ranging from 1 day to 1 month. They are attached to the low-tide shoreline or, occasionally, to the shore-parallel bar (Konicki and Holman 2000). Ribas and Kroon (2007) and Ribas et al. (2014) have shown that they are linked to the presence of obliquely incident waves that create a significant alongshore current, and that they are up-current oriented.

Type 3: Low-energy finger bars (Fig. 13.3c). These transverse bars are persistent features in fetch-limited beaches without a shore-parallel bar (Falqués 1989; Pellón et al. 2014). Bruner and Smosna (1989) and Pellón et al. (2014) gave information concerning both their orientation and the forcing direction. At the two sites, the bars were down-current oriented with respect to the alongshore current generated by the wind-waves. 

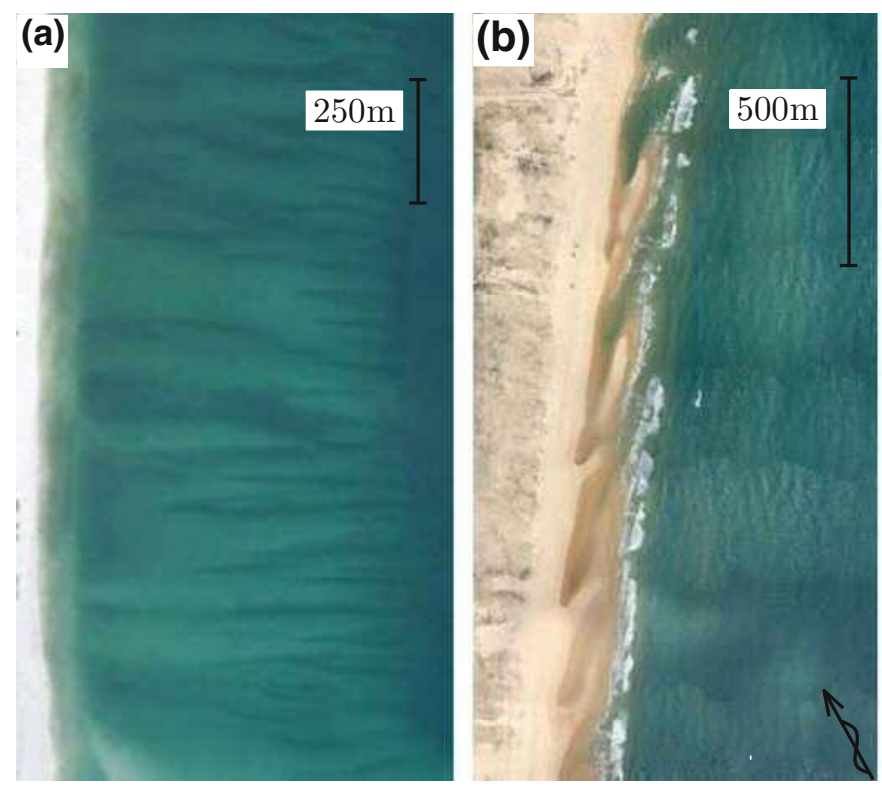

Fig. 13.3 Examples of observed transverse bars with different orientations: a shore-normal large-scale finger bars at Anna Maria Island, USA (Source Google Earth, US Geological Survey and USDA Farm Service Agency), b down-current-oriented TBR bars on the French Atlantic coast (Source Google Earth), c down-current-oriented

Type 4: Large-scale finger bars (Fig. 13.3a). These transverse bars have long cross-shore spans of $\mathrm{O}(1 \mathrm{~km})$ and develop across both the surf and the shoaling zone. They are generally observed to be persistent features in low-energy microtidal environments (Niedoroda and Tanner 1970; Gelfenbaum and Brooks 2003), and are typically oriented almost perpendicular to the shore. Although their dynamics is less well understood, the wave focusing caused by refraction of normal incident waves by the bars seems to be essential (Niedoroda and Tanner 1970).

\subsection{Physical Processes for Their Development and Dynamics}

\subsubsection{Shore-Parallel Straight Bars}

According to the widely accepted beach state classification (Wright and Short 1984), shore-parallel bars occur under moderate-energy conditions. In the situations when sand bars are alongshore uniform, it is commonly assumed that cross-shore rather than alongshore processes control the formation and migration of bars (Fernández-Mora et al. 2015). During storms, intense breaking of strong waves drives near-bottom offshore-directed flow (undertow) that transports sand offshore, causing the offshore migration of the bars. Onshore bar migration occurs under intermediate wave conditions, when the undertow is less intense and the
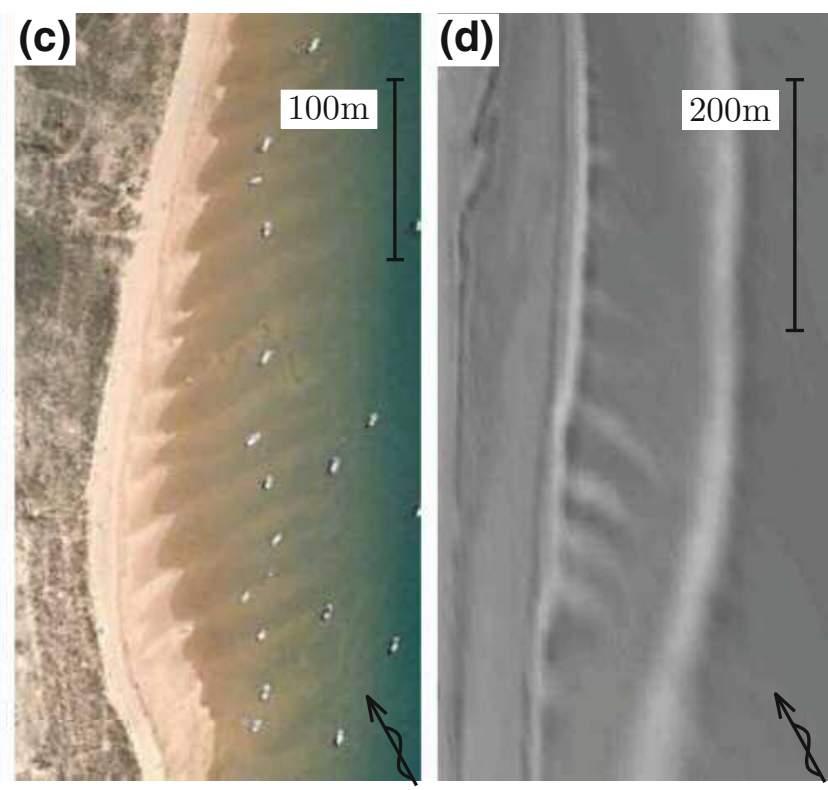

low-energy finger bars at El Puntal, Santander, Spain (Source Google Earth) and d up-current-oriented medium-energy finger bars at Noordwijk, the Netherlands (time-averaged video image). The coastline is on the left. Figure from Ribas et al. (2015)

cross-shore sediment transport is mainly due to wave non-linearity (velocity skewness and acceleration skewness). Recent process-based models have been able to reproduce these processes separately (Fernández-Mora et al. 2015; Dubarbier et al. 2015) but such models are still struggling to reproduce both processes accurately without changing the parameter values. Finally, the inter-annual net offshore migration of straight bars is accepted to be the result of gradual onshore movement during calm periods combined with episodic strong offshore movement during storms (van Enckevort and Ruessink 2003; Walstra et al. 2014).

Although the processes behind the cross-shore migration of shore-parallel bars are relatively well-known, the causes of initial bar formation are not yet clear (Wijnberg and Kroon 2002; Aagaard et al. 2008) and it is unknown whether bars detach from the shoreline (as argued in, e.g., Walstra et al. 2014) and then subsequently migrate offshore, or accrete in situ at some distance from the shoreline, in the commonly accepted framework of the breakpoint hypothesis (in which the bar forms near the break point of the incident waves, e.g. Mariño-Tapia et al. (2007)). The main reason for this uncertainty is that detailed experimental data during bar formation (including current and sediment transport measurements) are scarce. Aagaard et al. (2008) documented in detail the formation of a straight bar in the inner surf zone of a Danish beach, in which an erosion-accretion cross-shore pattern (generated by cross-shore variations in the speed and direction of the cross-shore transport processes discussed in 
the paragraph above) created the simultaneous development of a new trough near the shoreline and a bar further seaward. The cross-shore sediment transport gradients are due to a delicate balance between the offshore transport driven by undertow and the onshore transport driven by wave asymmetry, processes that are not yet well understood. Consequently, numerical sediment transport models often have difficulties simulating the initiation of a new bar-trough development (e.g. Mariño-Tapia et al. 2007).

\subsubsection{Crescentic Bars and Transverse TBR Bars (Type 1)}

Crescentic bars and TBR bars also occur on medium sand beaches under moderate-energy conditions (Wright and Short 1984). Within that framework, crescentic bars develop out of a straight bar for decreasing wave energy and TBR bars develop when the crescentic bar welds to the shore. With increasing wave energy when a storm arrives, the system experiences a reverse (up-state) transition, developing again into a straight, shore-parallel bar. The latter process is called bar straightening or morphological reset, and for decades it was simply associated with high-energy waves. However, recent studies have stressed the important role of wave obliquity in the transitions between a straight and a crescentic bar, revisiting the traditional classification. They found that crescentic bars develop mainly for normal wave incidence and bar straightening occurs for high oblique waves (Price and Ruessink 2011).

Results of recent morphodynamic models indicate the same tendency (Calvete et al. 2005; Garnier et al. 2008, 2013). In the framework of these models, the physical mechanism for crescentic bar formation is the coupling between the morphology and the induced rip-current circulation (self-organization). First, an incipient crescentic bar creates a pattern of wave breaking (waves break stronger on the shoals), which creates extra shoreward-directed forces and an over-elevation occurs on the shoreward part of the shoals. Small feeder currents flow from there to the shoreward part of the rip channels and flow offshore through these channels as rip currents. The circulation cells close due to wide onshore currents over the shoals. Second, since waves break somewhere on the seaward flank of the shore-parallel bar, there is a maximum in the depth-averaged sediment concentration (DASC) there. The onshore currents over the shoals flow to regions with less sediment load and thereby deposit sediment to the shoals, and the opposite occurs in the channels, where sediment is eroded. This is called positive feedback and the crescentic bar continues growing. Alongshore migration of crescentic bars is produced by obliquely incident waves, due to a downdrift shift of the rip-current circulation (Garnier et al. 2008). Bar straightening can also be understood with the same mechanisms: in cases of significant wave obliquity, the generated alongshore current weakens the rip-current circulation and shifts it downdrift, so alongshore migration is induced and the positive feedback weakens so much that the bar eventually becomes straight. A more detailed explanation can be found in Ribas et al. (2015).

\subsubsection{Transverse Medium-Energy Finger Bars (Type 2)}

Shore-oblique finger bars like the up-current-oriented, transverse medium-energy finger bars always coexist with a significant alongshore current. In such conditions, hydrodynamic processes that induce a meandering of the alongshore current can be more important than the breakinginduced currents of the previous section. Measurements of the hydrodynamics occurring over these bars are not available, but models have proved that, due to frictional forces and mass conservation, the alongshore current experiences a seaward deflection over up-current-oriented bars (and a shoreward deflection over the up-current troughs) (Garnier et al. 2006; Ribas et al. 2012). Moreover, these medium-energy finger bars occur in the steep inner surf zone of beaches with shore-parallel bars. In this situation, incident waves shoal before the crest of the shore-parallel bar, break over the bar, then reform over the trough, and finally break again in the inner surf zone. Somewhere in the inner surf zone, a local maximum in the DASC occurs, related to the second breaker zone, and it turns out to be located close to the shoreline because (i) strong breaking-induced turbulent vortices occur near the shore, (ii) waves dissipate their remaining energy in a relatively narrow area and (iii) the local maximum in the alongshore current profile is quite close to the shoreline. Thereby, up-current-oriented bars grow because the shoreward increasing DASC enhances the convergence of sediment transport in the seaward-directed current that occurs over the up-current crests (Garnier et al. 2006; Ribas et al. 2012).

\subsubsection{Transverse Low-Energy and Large-Scale Finger Bars (Types 3 and 4)}

For the case of low energy and large scale finger bars, there have been few observations of the induced currents but they indicate the same type of circulation as for the TBR bars. An interesting experiment in a laboratory wave basin was performed by Niederoda and Tanner (1970). On a shore-normal 
(short-crested) finger bar, an onshore current was measured over the bar crest and it diverged close to the beach to flow in the seaward direction through the troughs. An onshore-directed current over the crest of a low-energy finger bar (with a shore-oblique orientation) was also observed in the field by Falqués (1989). The physical processes driving this hydrodynamic circulation over approximately shore-normal transverse bars can be qualitatively explained by the focusing of wave energy (due to wave refraction and breaking) that occurs over transverse bars, which creates the onshore-directed currents. In the case of down-current-oriented bars, the alongshore current veers toward the shore over the crests and toward the sea over the troughs, so the corresponding current perturbations are reinforced by those created by wave-induced forces. These low-energy and large-scale finger bars typically emerge in terraced profiles with gentle slopes under normal and oblique waves. Waves dissipate their energy slowly across a wide-saturated surf zone, with the wave orbital velocity amplitude decreasing onshore across the surf zone. In the case of oblique wave incidence, an alongshore current is also generated, and typically has a maximum somewhere in the middle of the surf zone. Under such conditions, the combined action of the wave orbital velocities and the depth-averaged current produces a DASC profile that has a maximum in the outer part of the surf zone. Thereby, down-current or shore-normal transverse bars, with their onshore current perturbations on the crests, grow due to positive feedback created by the seaward increasing DASC (Garnier et al. 2006).

Acknowledgments This research has been funded by the Spanish government through the research projects CTM2012-35398 (cofunded by FEDER, U.E.) and CTM2015-66225-C2-1-P (MINECO/FEDER).

\section{References}

Aagaard, T., A. Kroon, M. G. Hughes and B. Greenwood (2008). Field observations of nearshore bar formation, Earth Surf. Process. Landforms 33, 1021-1032, doi:10.1002/esp.1599.

Bruner, K. R., and R. A. Smosna (1989). The movement and stabilization of beach sand on transverse bars, Assateague Island, Virginia, J. Coastal Res., 5(3), 593-601.

Dubarbier, B., B. Castelle, V. Marieu and G. Ruessink (2015). Process-based modeling of cross-shore sandbar behavior, Coastal. Eng., 95, 35-50, doi:10.1016/j.coastaleng.2014.09.004.

Calvete, D., N. Dodd, A. Falqués, and S. M. van Leeuwen (2005). Morphological development of rip channel systems: Normal and near normal wave incidence, J. Geophys. Res., 110(C10006), doi:10.1029/2004JC002803.

Castelle, B., P. Bonneton, N. Senechal, H. Dupuis, R. Butel, and D. Michel (2006). Dynamics of wave-induced currents over an alongshore non-uniform multiple-barred sandy beach on the Aquitanian Coast, France, Cont. Shelf Res., 26(1), 113-131, doi:10.1016/j.csr.2005.08.027.

Falqués, A. (1989). Formación de topografía rítmica en el Delta del Ebro, Revista de Geofísica, 45(2), 143-156.

Fernández-Mora, A., D. Calvete, A. Falqués, and H. E. de Swart (2015). Onshore sandbar migration in the surf zone: New insights into the wave-induced sediment transport mechanisms, Geophys. Res. Lett., 42, doi:10.1002/2014GL063004.

Garnier, R., D. Calvete, A. Falqués, and M. Caballeria (2006). Generation and nonlinear evolution of shore-oblique/transverse sand bars, J. Fluid Mech., 567, 327-360, doi:10.1017/ S0022112006002126.

Garnier, R., D. Calvete, A. Falqués, and N. Dodd (2008). Modelling the formation and the long-term behavior of rip channel systems from the deformation of a longshore bar, J. Geophys. Res., 113(C07053), doi:10.1029/2007JC004632.

Garnier, R., A. Falqués, D. Calvete, J. Thiébot, and F. Ribas (2013). A mechanism for sandbar straightening by oblique wave incidence, Geophys. Res. Lett., 40, 2726-2730, doi:10.1002/grl.50464.

Gelfenbaum, G., and G. R. Brooks (2003). The morphology and migration of transverse bars off the west-central Florida coast, Mar. Geol., 200, 273-289, doi:10.1016/S0025-3227(03)00187-7.

Guillén, J., and A. Palanques (1993). Longshore bar and trough systems in a microtidal, storm-wave dominated coast: The Ebro Delta (Northwestern Mediterranean), Mar. Geol., 115, 239-252, doi:10. 1016/0025-3227(93)90053-X.

Holman, R. A., G. Symonds, E. B. Thornton, and R. Ranasinghe (2006). Rip spacing and persistence on an embayed beach, J. Geophys. Res., 111, C01006, doi:10.1029/2005JC002965.

Hunter, R. E., H. E. Clifton, and R. L. Phillips (1979). Depositional processes, sedimentary structures, and predicted vertical sequences in barred nearshore systems, Southern Oregon coast, J. Sediment. Petrol., 49(3), 711-726, doi:10.1306/212F7824-2B24-11D7$8648000102 \mathrm{C} 1865 \mathrm{D}$.

Konicki, K. M., and R. A. Holman (2000). The statistics and kinematics of transverse bars on an open coast, Mar. Geol., 169, 69-101, doi:10.1016/S0025-3227(00)00057-8.

Mariño-Tapia, I. J., T. J. O’Hare, P. E. Russell, M. A. Davidson and D. A. Huntley (2007). Cross-shore sediment transport on natural beaches and its relation to sandbar migration patterns: 2. Application of the field transport parameterization. J. Geophys. Res. 112, C03002, doi: $10.1029 / 2005$ JC002893

Niederoda, A. W., and W. F. Tanner (1970). Preliminary study on transverse bars, Mar. Geol., 9, 41-62, doi:10.1016/0025-3227(70) 90079-4.

Ojeda, E., J. Guillén and F. Ribas (2011). Dynamics of single-barred embayed beaches, Mar. Geol., 280, 76-90, doi:10.1016/j.margeo. 2010.12.002.

Pellón, E., R. Garnier, and R. Medina (2014). Intertidal finger bars at El Puntal, Bay of Santander, Spain: Observation and forcing analysis, Earth Surf. Dyn., 2, 349-361, doi:10.5194/esurf-2-349-2014. 
Price, T. D., and B. G. Ruessink (2011). State dynamics of a double sandbar system, Cont. Shelf Res., 31, 659-674, doi:10.1016/j.csr. 2010.12.018

Ranasinghe, R., G. Symonds, K. Black, and R. Holman (2004). Morphodynamics of intermediate beaches: A video imaging and numerical modelling study, Coastal Eng., 51, 629-655, doi:10. 1016/j.coastaleng.2004.07.018.

Ribas, F., and A. Kroon (2007). Characteristics and dynamics of surfzone transverse finger bars, J. Geophys. Res., 112, F03028, doi:10.1029/2006JF000685.

Ribas, F., A. ten Doeschate, H. E. de Swart, G. Ruessink, and D. Calvete (2014). Observations and modelling of surf-zone transverse finger bars, Ocean Dyn., 64, 1193-1207, doi:10.1007/s10236-014$0719-4$.

Ribas, F., A. Falqués, H. E. de Swart, N. Dodd, R. Garnier, and D. Calvete (2015). Understanding coastal morphodynamic patterns from depth-averaged sediment concentration, Rev. Geophys., 53, doi:10.1002/2014RG000457.

Ribas, F., A. Falqués and R. Garnier (2016). Nearshore sand bars on western Mediterranean beaches, in Atlas of Bedforms in the Western Mediterranean, ch. 14, Springer, ISBN: 978-3-319-33940-5.

Ribas, F., H. E. de Swart, D. Calvete, and A. Falqués (2012). Modeling and analyzing observed transverse sand bars in the surf zone, J. Geophys. Res., 117, F02013, doi:10.1029/2011JF002158.
Ruessink, B. G., L. Pape, I. L. Turner (2009). Daily to interannual cross-shore sandbar migration: Observations from a multiple sandbar system, Cont. Shelf Res., 29, 1663-1677, doi:10.1016/j. csr.2009.05.011.

Van Enckevort, I. M. J., and B. G. Ruessink (2003). Video observations of nearshore bar behaviour. Part 1: alongshore uniform variability, Cont. Shelf Res., 23, 501-512, doi:10.1016/S0278-4343(02)002340 .

Van Enckevort, I. M. J., B. G. Ruessink, G. Coco, K. Suzuki, I. L. Turner, N. G. Plant, and R. A. Holman (2004). Observations of nearshore crescentic sandbars, J. Geophys. Res., 109 (C06028), doi:10.1029/2003JC002214.

Walstra, D. J. R., B. G. Ruessink, A. J. H. M. Reniers and R. Ranasinghe (2014). Process-based modeling of kilometer-scale alongshore sandbar variability, Earth Surf. Process. Landforms, doi:10.1002/esp.3676.

Wijnberg, K.M., and A. Kroon (2002). Barred beaches, Geomorphology, 48, 103-120.

Wright, L. D., and A. D. Short (1984). Morphodynamic variability of surf zones and beaches: A synthesis, Mar. Geol., 56, 93-118, doi:10.1016/0025-3227(84)90008-2. 